\title{
Efficacy, Tolerability, and Safety of Concentrated Intranasal Midazolam Spray as Emergency Medication in Epilepsy Patients During Video-EEG Monitoring
}

\author{
Anemone von Blomberg ${ }^{1,2} \cdot$ Lara Kay $^{1,2} \cdot$ Susanne Knake ${ }^{2,3} \cdot$ Sven Fuest ${ }^{3} \cdot$ Johann Philipp Zöllner ${ }^{1,2}$. \\ Philipp S. Reif ${ }^{1,2}$ - Eva Herrmann ${ }^{4}$. Ümniye Balaban ${ }^{4}$. Susanne Schubert-Bast ${ }^{1,2,5}$. Felix Rosenow ${ }^{1,2}$. \\ Adam Strzelczyk ${ }^{1,2,3}$
}

Published online: 26 March 2020

(c) The Author(s) 2020

\begin{abstract}
Background An efficient, well tolerated, and safe emergency treatment with a rapid onset of action is needed to prevent seizure clusters and to terminate prolonged seizures and status epilepticus.

Objectives This study aimed to examine the efficacy, tolerability, and safety of intranasal midazolam (in-MDZ) spray in clinical practice.

Methods In this retrospective, multicenter observational study, we evaluated all patients with peri-ictal application of inMDZ during video-EEG monitoring at the epilepsy centers in Frankfurt and Marburg between 2014 and 2017. For every patient, we analyzed the recurrence of any seizure or generalized tonic-clonic seizures after index seizures with and without in-MDZ administration. Treatment-emergent adverse events (TEAEs) were also evaluated.

Results In-MDZ was used in 243 patients with epilepsy (mean age 35.5 years; range 5-76 years; $46.5 \%$ female) for treatment of 459 seizures. A median dose of in-MDZ $5 \mathrm{mg}$ (i.e., two puffs; range $2.5-15 \mathrm{mg}$ ) was administered within a median time from EEG seizure onset until in-MDZ application of $1.18 \mathrm{~min}$ [interquartile range (IQR) 1.27], while median time from clinical seizure onset until in-MDZ administration was $1.08 \mathrm{~min}$ (IQR 1.19). In-MDZ was given within 1 min after EEG seizure onset in 171 seizures. An intraindividual comparison of seizures with and without application of in-MDZ was feasible in 171 patients, demonstrating that in-MDZ reduced the occurrence of any (Cox proportional-hazard model $p<0.001$ ) and generalized tonic-clonic seizure (Cox proportional-hazard model $p=0.0167$ ) over a period of $24 \mathrm{~h}$. The seizure-free timespan was doubled from a median of $5.0 \mathrm{~h}$ in controls to a median of $10.67 \mathrm{~h}$ after in-MDZ administration. We additionally clustered in-MDZ administrations for the 119 patients who received in-MDZ more than once, comparing them with the index cases without in-MDZ. Even when considering subsequent seizures with in-MDZ administration, a patient receiving in-MDZ is still half as likely to incur another seizure in the upcoming $24 \mathrm{~h}$ as compared with when the same patient does not receive in-MDZ (hazard ratio 0.50; 95\% CI 0.42-0.60; $p<0.01$ ). In-MDZ was well tolerated without major adverse events. The most common side effects were irritation of the nasal mucosa [37 cases (8.1\%)], prolonged sedation [26 cases (5.7\%)], and nausea and vomiting [12 cases (2.6\%)]. A decline in oxygen saturation was measured after 78 seizures (17\%).

Conclusion We conclude that in-MDZ is a safe and efficient treatment option to prevent short-term recurrence of seizures. InMDZ can be administered very quickly by trained staff within 1-2 min after seizure onset. No major cardiocirculatory or respiratory adverse events were observed.
\end{abstract}

\section{Introduction}

The emergency treatment of acute seizures is required to be rapid and efficient, as ongoing epileptic activity results in increased morbidity and mortality [1]. The ideal

Adam Strzelczyk

strzelczyk@med.uni-frankfurt.de

Extended author information available on the last page of the article anticonvulsant agent is safe, easily administered, and has a long-lasting antiseizure effect [2]. Rescue medication should prevent seizure recurrence as well as the occurrence of prolonged seizures or status epilepticus [3-5]. Benzodiazepines such as lorazepam, diazepam, and midazolam are established first-line drugs for acute seizures [6], with available delivery routes that include intravenous, rectal, intramuscular, buccal, and intranasal [5-11]. Difficulties with achieving intravenous access may lead to a delay in drug 


\section{Key Points}

Use of intranasal midazolam spray was analyzed in a large cohort ( $n=243 ; 459$ seizures) of patients with epilepsy.

In general, intranasal midazolam spray reduced the occurrence of any (Cox proportional-hazard model $p<0.001)$ and generalized tonic-clonic seizure ( $p=0.0167)$ over a period of $24 \mathrm{~h}$. The seizure-free timespan was doubled from a median of $5.0 \mathrm{~h}$ in controls to a median of $10.67 \mathrm{~h}$ after intranasal midazolam administration.

Intranasal midazolam spray can be administered easily and quickly after seizure onset by hospital staff. We did not observe any clinically relevant treatment-emergent effects.

administration, rendering the development of suitable nonparenteral routes vital, as responsiveness to benzodiazepines is time-dependent [12]. Jaw clenching [9], hypersalivation, and uncontrollable swallowing constitute some limitations inherent to the buccal route, making it difficult to minimize variability in pharmacodynamics [13], which might also prove problematic for intramuscular injections [8]. Rectal administration is becoming less popular due to the social distress and sense of shame it imposes on both patients and caregivers [14].

In comparison, intranasal midazolam (in-MDZ) may be a more favorable option as it can be administered in a significantly shorter interval without the need for an intravenous route [15] and has been shown to be reliable and efficient [8, 14-19]. Furthermore, as compared with rectal diazepam, it is at least as effective in its anticonvulsive action [14, 20, $21]$ and is preferred by caregivers [20, 22]. Additionally, in-MDZ can be easily administered, rendering drug delivery more convenient in cases where patients are cognitively impaired and gaining their cooperation is more difficult [8]. However, study populations have so far been small and data on adult patients remain relatively scarce [23, 24].

The aim of this study was to ascertain the efficacy, tolerability, and safety of in-MDZ during video-EEG monitoring.

\section{Methods}

In this retrospective, multicenter observational study, we examined the medical records of all patients with an epilepsy diagnosis who received in-MDZ during video-EEG monitoring between September 2014 and August 2017 at the university hospitals in Marburg and Frankfurt. Patients were admitted for presurgical evaluation or evaluation of their epilepsy syndrome, both usually scheduled for $120 \mathrm{~h}$ and requiring withdrawal of antiepileptic drugs. In both units, each patient is prescribed in-MDZ as a pro re nata emergency medication in case of frequent or prolonged seizures or generalized convulsive seizures; a dedicated emergency protocol is not utilized. Patients treated with in-MDZ between 2008 and 2014 who were previously analyzed and reported in a pilot study by Kay et al. [17] were not included.

All patients who received in-MDZ were identifiable through the narcotic drug documentation, which is mandatory for the use of concentrated midazolam nasal spray under Article III of German Narcotic Law. This is due to the fact that the midazolam content in one nasal spray device exceeds $15 \mathrm{mg}$. We included all patients with epilepsy and administration of in-MDZ. Patients in whom in-MDZ was administered for reasons other than seizure treatment (e.g., periprocedural sedation), or erroneously for treatment for psychogenic nonepileptic seizures, were excluded from analysis. The analysis was approved by the ethics committee of the Goethe-University Frankfurt and adhered to the Strengthening the Reporting of Observational Studies in Epidemiology (STROBE) statement [27]. The informed consent was waived by the ethics committees because of the retrospective nature of the study. This study was not sponsored or funded by any company.

Briefly, EEG, electrocardiogram (ECG), and video data were reviewed in patients who underwent video-EEG monitoring while in-MDZ was administered. Patients were monitored with scalp electrodes according to the 10-20 international system [25]. Sphenoidal electrodes or intracranial depth or subdural electrodes were placed in selected patients when clinically indicated. Heart rate analysis was based on the coregistered ECG tracing [29]. If available, the saturation of peripheral oxygen was measured interictally and immediately after a seizure using a pulse oximeter.

The classification of seizure types and epilepsies was performed based on the latest definitions proposed by the International League against Epilepsy (ILAE) [26, 28]. A standardized questionnaire was used to gather information concerning etiology, concomitant diseases, frequency of seizures, anticonvulsant treatment, and, if applicable, its discontinuation during the video-EEG monitoring.

EEG seizure onset and EEG seizure endpoint, and timing of in-MDZ treatment as well as seizure type were recorded. The following $24 \mathrm{~h}$ were examined for the occurrence of seizures. For every administration of midazolam, treatmentemergent adverse events (TEAEs) were recorded from the medical reports and the annotations to the video and EEG data if applicable, including a deterioration in oxygenation, nasal irritation, headache, cough, nausea and vomiting, and prolonged sedation. As proposed by Bancke et al. [30], we defined a drop of peripheral oxygen saturation below $90 \%$ to be a TEAE. Measurements of peripheral oxygen saturation were available in 310 out of 459 in-MDZ applications.

The concentrated midazolam spray was prepared by the central pharmacies of the involved university hospitals in Marburg 
and Frankfurt, based on a formula that was previously published [17, 31]. The clear and colorless solution contained midazolam hydrochloride buffered to a $\mathrm{pH}$ of 3.3 with a mixture of water and $1 \mathrm{~N}$ of hydrochloride acid. As an antimicrobial preservative, we used benzalkonium chloride and sodium ethylenediaminetetraacetic acid. Stored at room temperature and under light protection, the spray lasts up to 3 months. Medical personnel applying the nasal spray were trained to deliver the drug, ensuring standardized administration. To ensure equal dosage, nasal spray devices (Zscheile \& Klinger, Hamburg, Germany) were used and a dose of $2.5 \mathrm{mg}$ of midazolam per puff $(140 \mu \mathrm{L})$ was administered.

Intraindividual comparisons comparing index seizures with and without midazolam were performed to examine the potential effects of in-MDZ on increasing the seizure-free interval within the subsequent $24 \mathrm{~h}$ and the semiology of the upcoming seizure. For each patient, the timespan between seizures both with and without midazolam application and the respective following seizures were compared. To prevent potential bias, the first seizure with midazolam administration was defined as the in-MDZ index seizure and compared with the control index seizure without in-MDZ. The control index seizure was either the first seizure of the patient recorded via monitoring or, if no seizure prior to midazolam application was available, the first seizure after midazolam application without in-MDZ. If a patient received midazolam during more than one seizure, every application was recorded and assessed for tolerability and safety. Where patients received in-MDZ on several occasions, we additionally clustered in-MDZ administrations for every patient and compared them with the patients' respective index seizure without in-MDZ.

Statistic evaluations were executed using the SPSS version 25.0 software program (IBM Corp., Armonk, NY, USA) and R (R Foundation for Statistical Computing, Vienna, Austria). McNemar's test was used to determine if there are differences between the paired in-MDZ and control groups. The seizure-free interval and heart rate were nonnormally distributed and groups were compared using a Wilcoxon paired sample test. Seizure recurrence was depicted in survival curves and test comparisons from a Cox proportional-hazard model for both the in-MDZ and control groups using a clustering for individual patients. All $p$ values were two-sided and considered significant if $<0.05$.

\section{Results}

\subsection{Patient Characteristics}

In total, 243 patients [113 female $(46.5 \%)$ ] received inMDZ during the study period with sufficient EEG and video data for analysis (including 167 in Frankfurt and 76 in Marburg). The mean \pm standard deviation (SD) age was $35.5 \pm 14.5$ years [range 5-76 years, 19 patients below the age of 18 years $(7.8 \%)$ ], with a mean \pm SD age of epilepsy onset of $18.1 \pm 14.7$ years (range $0-64$ years). The overall mean \pm SD duration of epilepsy to the time of admission was $16.9 \pm 13.3$ years (range $0-60$ years). Patients reported a mean \pm SD of $19.4 \pm 99$ seizures per month (median 4 seizures; range $0-1500$ seizures), including $17.5 \pm 98.7$ focal seizures (median 2 seizures; range $0-1500$ seizures) and $1.2 \pm 3.9$ generalized tonic-clonic seizures (GTCS) [median 0.1 seizures; range $0-30$ seizures; 197 (81\%) patients had GTCS in their lifetime].

Patients were found to be taking a mean of $2.2 \pm 0.9$ antiseizure drugs (ASDs) (range 0-4), with 50 (20.6\%) of them taking monotherapy, 190 (78.2\%) taking polytherapy, and three $(1.2 \%)$ being currently without any medication. The patients had failed a mean \pm SD of $2.6 \pm 2.5$ ASDs in the past (median 2 ASDs; range 0-15 ASDs; current medications not included). In total, 224 patients $(92.2 \%)$ had drugresistant epilepsy according to the definition of the ILAE [32]. Fourteen (5.8\%) patients had undergone neurosurgery for the implantation of electrodes prior to the monitoring.

The most prevalent epilepsy type was focal $(91.0 \%)$, followed by generalized epilepsy $(7.0 \%)$, while the epilepsy syndrome remained unknown in $2.1 \%$. A total of 141 patients $(58.0 \%)$ had additional medical conditions and, in 40 cases $(16.5 \%)$, neurological impairments were present. For a more detailed description of patient characteristics, see Table 1 .

\subsection{Characteristics, Tolerability, and Safety of in-MDZ Application During Video-EEG Monitoring}

Video-EEG monitoring was performed for a mean \pm SD of $113.9 \pm 34.1 \mathrm{~h}$ (median 107; range 47-254). In the majority $(n=232 ; 95.5 \%)$ of patients, antiseizure medication was reduced or discontinued during video-EEG monitoring, while, in nine patients (3.7\%), medication use was unchanged and two patients $(0.8 \%)$ did not receive ASD treatment. Overall, midazolam was used 459 times (cases), with 119 patients receiving in-MDZ more than once. Patients received in-MDZ during or after a GTCS in 184 cases (40.1\%), 261 times due to focal seizures (56.9\%), and in 14 cases $(3 \%)$ in-MDZ was given due to unstable EEG patterns. A median dose of in-MDZ $5 \mathrm{mg}$ (i.e., two puffs; SD $1.2 \mathrm{mg}$; range $2.5-15 \mathrm{mg}$ ) was administered; the median was lower $(3.75 \mathrm{mg})$ in those aged 12 years and younger, and $5 \mathrm{mg}$ in the elderly aged 60 years and older.

The median time from EEG seizure onset until in-MDZ application was 1.18 min [interquartile range (IQR) 1.27; range 0.1-52.4], while median time from clinical seizure onset until in-MDZ administration was 1.08 min (IQR 1.19; 
Table 1 Clinical characteristics of patients treated with intranasal midazolam (in-MDZ)

\begin{tabular}{|c|c|}
\hline Patients treated with in-MDZ $(n=243)$ & $\%(n)$ \\
\hline Age in years $($ mean $\pm \mathrm{SD})$ & $35.5 \pm 14.5$ \\
\hline Age at epilepsy onset $($ mean \pm SD) & $18.1 \pm 14.7$ \\
\hline Epilepsy duration in years (mean $\pm \mathrm{SD}$ ) & $16.9 \pm 13.3$ \\
\hline \multicolumn{2}{|l|}{ Epilepsy type } \\
\hline Focal epilepsy & $86.4(210)$ \\
\hline Right hemisphere & $34.2(83)$ \\
\hline Left hemisphere & $39.9(97)$ \\
\hline Bilateral & $12.3(30)$ \\
\hline Genetic (idiopathic) generalized epilepsy & $6.2(15)$ \\
\hline Unknown & $7.4(18)$ \\
\hline \multicolumn{2}{|l|}{ History of status epilepticus } \\
\hline Yes & $4.1(10)$ \\
\hline No & $95.9(233)$ \\
\hline \multicolumn{2}{|l|}{ History of febrile convulsions } \\
\hline Yes & $9.9(24)$ \\
\hline No & $84.8(206)$ \\
\hline Unknown & $5.3(13)$ \\
\hline \multicolumn{2}{|l|}{ Imaging findings } \\
\hline No appreciable disease & $37.2(96)$ \\
\hline Cavernoma & $3.5(9)$ \\
\hline Cortical dysplasia & $14.0(36)$ \\
\hline Hippocampal sclerosis & $22.1(57)$ \\
\hline Tumor & $9.7(25)$ \\
\hline Other & $7.0(18)$ \\
\hline No imaging available & $3.5(9)$ \\
\hline Previous neurosurgery & $3.1(8)$ \\
\hline \multicolumn{2}{|l|}{ Comorbidities $(n=141)$} \\
\hline Arterial hypertension & $15.6(22)$ \\
\hline Diabetes & $6.4(9)$ \\
\hline Adipositas & $5.7(8)$ \\
\hline Depression & $19.1(27)$ \\
\hline Psychiatric conditions & $11.3(16)$ \\
\hline Endocrine disease & $9.9(14)$ \\
\hline Abuse of alcohol & $4.3(6)$ \\
\hline Abuse of nicotine & $17.7(25)$ \\
\hline Other & $9.9(14)$ \\
\hline \multicolumn{2}{|l|}{ Antiseizure drugs } \\
\hline Levetiracetam & $60.9(148)$ \\
\hline Lamotrigine & $42.8(104)$ \\
\hline Lacosamide & $18.5(45)$ \\
\hline Oxcarbazepine & $17.3(42)$ \\
\hline Zonisamide & $16.0(39)$ \\
\hline Valproate & $12.8(31)$ \\
\hline Carbamazepine & $10.7(26)$ \\
\hline Topiramate & $7.4(18)$ \\
\hline Other & $30.0(73)$ \\
\hline
\end{tabular}

range -0.25 to 52.3 ); in one case, in-MDZ was administered before clinical seizure onset. In-MDZ was given within 1 min after EEG seizure onset in 171 cases.

We observed some kind of TEAE in 108 (44.4\%) patients and 136 cases $(29.6 \%)$. TEAEs included irritation of the nasal mucosa ( $n=32$ patients, $13.2 \%$; 37 cases, $8.1 \%$ ), headache $(n=4$ patients, $1.6 \% ; 4$ cases, $0.9 \%)$, cough $(n=8$ patients, $3.3 \%$; 9 cases, $2.0 \%$ ), nausea and vomiting ( $n=10$ patients, $4.1 \% ; 12$ cases, $2.6 \%)$, and prolonged sedation ( $n=22$ patients, $9.1 \%$; 26 cases, $5.7 \%$ ). One patient had a nosebleed following several attempts to administer the drug despite excessive turning of the head.

Heart rate analysis showed a comparable increase of heart rate $10 \mathrm{~min}$ after GTCS (29.3 bpm in in-MDZ; $25.8 \mathrm{bpm}$ in controls) and $10 \mathrm{~min}$ after seizures without generalization (5.3 bpm in in-MDZ, $4.0 \mathrm{bpm}$ in controls) with and without in-MDZ.

In 310 seizures, the measurement of oxygen saturation was feasible. Oxygen levels were measured directly after seizure end, which occurred a median of $3.43 \mathrm{~min}$ after application of in-MDZ. The mean \pm SD oxygen saturation immediately postictally being $92.3 \% \pm 6 \%$ (range 51-99). There was no intubation necessary in any patient. A drop in peripheral oxygen saturation below $90 \%$ occurred 78 times (17\%) in 67 patients (27.6\%). Such a desaturation below $90 \%$ was observed 36 times after seizures without generalization and in 42 GTCS. Among the latter, one patient had respiratory insufficiency with a minimum oxygen concentration of $51 \%$ after having suffered a GTCS. Oxygenation rose above $90 \%$ within 42 s under administration of oxygen.

\subsection{Difference in Number of Recurring Seizures with and without Administration of in-MDZ}

To evaluate the difference in number of recurring seizures for a postictal period of $24 \mathrm{~h}$, we compared pairs of seizures in each single patient, with and without administration of inMDZ. Overall, 171 pairs of seizures with in-MDZ application and seizures without treatment were suitable for statistic comparison. Regarding generalization, we observed a higher proportion of GTCS for index seizures treated with in-MDZ $(60 / 171 ; 35.1 \%)$ than for controls $(16 / 171 ; 9.4 \% ; p<0.001)$. In 72 patients, there was no index seizure without in-MDZ available because the patients either received in-MDZ in every seizure ( $n=69$ patients; $28.4 \%$ ); were treated with inMDZ due to unstable EEG patterns ( $n=2$ patients; $0.8 \%$ ); or the EEG pattern could not be clearly distinguished in the index seizure without in-MDZ $(n=1)$. These patients were included in the study for tolerability assessment only.

Among 116 patients, the index seizure without in-MDZ took place a median of $17.28 \mathrm{~h}$ before the in-MDZ seizure (IQR 25.34; range 0.15-209.12), whereas in 52 patients, the index seizure without in-MDZ took place a median of 


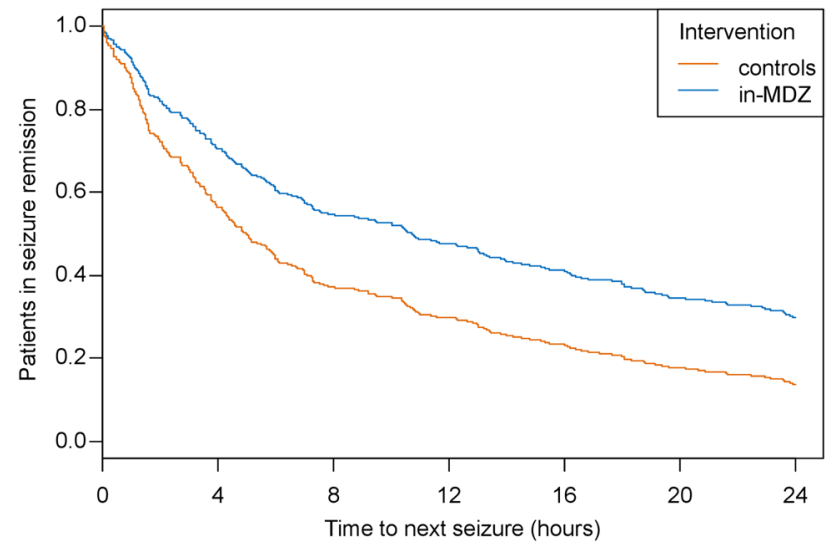

Fig. 1 Time to seizure recurrence after index seizure with or without application of intranasal midazolam for an observation period of $24 \mathrm{~h}$. Results from a Cox-regression approach are shown using clusters for individual patients $(p<0.001$; hazard ratio $0.61 ; 95 \%$ confidence interval 0.49-0.76). in- $M D Z$ intranasal midazolam

$9.03 \mathrm{~h}$ after the in-MDZ index seizure (IQR 16.85; range $0.69-143.95)(p<0.001)$. The seizure-free interval as per intention-to-treat analysis is depicted in a survival curve in Fig. $1(p<0.001)$. Further, the median timespan until the occurrence of the next seizure was $10.67 \mathrm{~h}$ [range 0.03-24, 95\% confidence interval (CI) 7.28-14.77] after the application of in-MDZ, which was a significantly longer period than that after the index seizure without in-MDZ $(5.00 \mathrm{~h}$; range 0.02-24 h, 95\% CI 4.12-6.55).

In-MDZ had a significant effect on seizure recurrence within the upcoming $24 \mathrm{~h}$. Of the total cohort, $93.6 \%$ of patients remained seizure-free for $60 \mathrm{~min}$ following in-MDZ (vs $85.4 \%$ without in-MDZ), $60.8 \%$ remained seizure-free for $6 \mathrm{~h}$ (vs 43.9\% without in-MDZ), and 29.2\% did not experience another seizure in the following $24 \mathrm{~h}$ (vs $14 \%$ without in-MDZ).
The rate of GTCS in the following 24-hour interval was lower in the in-MDZ group than that in the control group for the same time period (see Table 2). The recurrence of GCTS within $24 \mathrm{~h}$ is depicted as a survival curve as per intentionto-treat analysis in Fig. 2 ( $p$ value $=0.0167$ ).

To increase the validity of our findings, we additionally clustered in-MDZ administrations for the 119 patients who received in-MDZ more than once, comparing them to the index cases without in-MDZ. We found that, even when considering subsequent seizures with in-MDZ administration, a patient receiving in-MDZ is still half as likely to incur another seizure in the upcoming $24 \mathrm{~h}$ as compared with when the same patient does not receive in-MDZ (hazard ratio $0.50 ; 95 \%$ CI $0.42-0.60$ ). This finding was statistically significant with $p<0.01$.

\section{Discussion}

Our study indicates that in-MDZ can be used as an effective anticonvulsant agent in emergency seizure treatment for epilepsy patients, in that it reduces seizure recurrence within the upcoming $24 \mathrm{~h}$ and does not cause any serious adverse events.

Previous research in children and smaller cohorts has already suggested in-MDZ to be a recommendable alternative to rectal diazepam [18, 33], intravenous diazepam [24], and intravenous lorazepam both in terms of comfort of drug delivery and effect. In their comparison of in-MDZ with intravenous diazepam, Lahat et al. [24] showed intravenous diazepam to have a more rapid effect, but the time until drug delivery was longer and thus in-MDZ was more favorable in terms of time until seizure cessation. Fişgin et al. [16] concluded that intranasal midazolam was more effective than rectal diazepam in terminating seizures, ending $87 \%$

Table 2 Occurrence of any seizure and of generalized tonic-clonic seizure (GTCS) in patients with and without application of intranasal midazolam (in-MDZ)

\begin{tabular}{|c|c|c|c|c|c|c|c|}
\hline \multirow[t]{2}{*}{ Time (h) } & \multicolumn{3}{|c|}{ Index seizure with in-MDZ treatment } & \multicolumn{3}{|c|}{ Index seizure without in-MDZ treatment } & \multirow[t]{2}{*}{$p$ value* } \\
\hline & $\begin{array}{l}\text { No seizure recurrence } \\
\text { (no. of patients) }\end{array}$ & $\begin{array}{l}\text { Seizure recurrence } \\
\text { (no. of patients) }\end{array}$ & $\begin{array}{l}\text { Patients } \\
\text { with GTCS }\end{array}$ & $\begin{array}{l}\text { No seizure recurrence } \\
\text { (no. of patients) }\end{array}$ & $\begin{array}{l}\text { Seizure recurrence } \\
\text { (no. of patients) }\end{array}$ & $\begin{array}{l}\text { Patients } \\
\text { with GTCS }\end{array}$ & \\
\hline 1 & 160 & 11 & 0 & 146 & 25 & 3 & $<0.001$ \\
\hline 2 & 143 & 28 & 1 & 121 & 50 & 6 & $<0.001$ \\
\hline 3 & 134 & 37 & 2 & 110 & 61 & 8 & $<0.001$ \\
\hline 4 & 126 & 45 & 3 & 91 & 80 & 11 & 0.002 \\
\hline 5 & 115 & 56 & 5 & 82 & 89 & 14 & 0.080 \\
\hline 6 & 104 & 67 & 8 & 75 & 96 & 16 & 0.621 \\
\hline 9 & 90 & 81 & 10 & 64 & 107 & 19 & 0.254 \\
\hline 12 & 80 & 91 & 10 & 52 & 119 & 21 & 0.007 \\
\hline 24 & 50 & 121 & 18 & 24 & 147 & 25 & $<0.001$ \\
\hline
\end{tabular}

*McNemar's test 


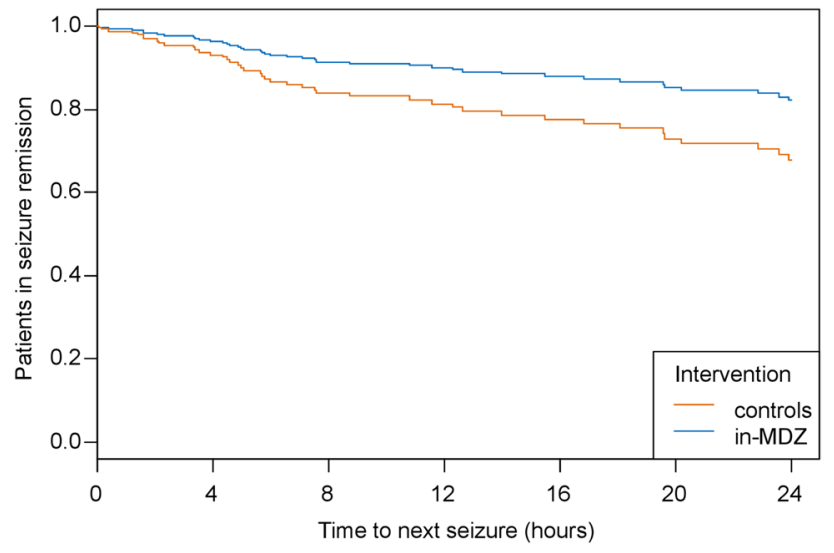

Fig. 2 Time to occurrence of a generalized tonic-clonic seizure after index seizure with or without application of intranasal midazolam for an observation period of $24 \mathrm{~h}$. Patients with recurrence of any seizure were censored. Results from a Cox-regression approach are shown using clusters for individual patients $(p=0.0167$; hazard ratio 0.51 ; 95\% confidence interval 0.29-0.88). in- $M D Z$ intranasal midazolam

as opposed to $60 \%$ of seizures within $10 \min (p<0.05)$. With special consideration of seizure prevention, Kay et al. [17] examined the medical records of 75 patients with an overall 110 applications of in-MDZ. Comparing 63 pairs of seizures intraindividually with and without in-MDZ, they found seizure recurrence to have been successfully prevented by inMDZ and the seizure-free time span to have been increased significantly to a median of $5.8 \mathrm{~h}$ as compared with $2.4 \mathrm{~h}$ in patients without in-MDZ.

Our aim in this study was to validate these prior findings further using a larger sample of 243 patients, 459 seizures and 171 intraindividual comparisons overall. We found a positive effect for seizure recurrence for the 6-, 12- and 24-h intervals following a seizure with in-MDZ application. We confirmed this effect for the 24-h interval upon clustering seizure data for patients receiving in-MDZ on several occasions. This suggests that repeated drug administration has an equally beneficial effect on seizure prevention and there is no deterioration of the effect due to tolerance induction. Furthermore, we observed a difference in the deterioration of seizures into GTCS, with fewer patients experiencing a GTCS in the upcoming seizure after having received in-MDZ than without.

Our findings are supported by Detyniecki et al. [34], who conducted an open-label extension study involving 161 patients that examined the safety profile and seizurerelated outcomes of in-MDZ in an outpatient setting. Seizure recurrence in their trial was $31 \%$ within $6 \mathrm{~h}$, comparable to $39.5 \%$ in our study. Regarding the $24-\mathrm{h}$ interval, these authors found seizure recurrence to be $36.9 \%$, which was considerably less than our result of $70.1 \%$. This may be due to the fact that they did not discontinue ASDs, as well as a result of limited surveillance since, in their study, follow-up observation was carried out by caregivers only. In our study design, only hospitalized patients were included so as to be able to ascertain the availability of the time of seizure onset, delivery of the study drug, and seizure termination. Thus, patients were under constant video-EEG monitoring and seizure recurrence was thus much more likely to be detected.

In-MDZ seems to be a safe treatment measure, but, as with any drug, it has weaknesses. Detyniecki et al. [34] detected TEAEs in $57.1 \%$ of patients $(n=161)$, mainly nasal irritation (12.4\%) and somnolence (9.3\%). Kay et al. [17] $(n=75)$ observed some side effects in four patients (5.3\%), with three showing nasal irritation and one patient delaying the application of the study drug due to peri-ictal movement of the head. In a study of 21 patients, De Haan et al. [33] reported $68 \%$ of in-MDZ administrations $(n=59)$ to have caused drowsiness, while $29 \%$ led to nasal irritation. In our study and in accordance with the findings mentioned above, we observed various side effects in 108 (44.4\%) patients. The main TEAEs included a drop in peripheral oxygen levels, nasal irritation, prolonged sedation, and nausea and vomiting. One patient had respiratory depression, but he recovered quickly after oxygen was applied and no intubation was necessary. Oxygen levels of all other patients recovered within seconds after seizure cessation. No major adverse events were detected that required additional medical assistance. Midazolam and benzodiazepines in general are known for their potential for respiratory depression [35]. In our study, desaturation occurred 78 times (17\%). The number of patients with postictally reduced oxygen saturation is similar or rather low when compared with results of dedicated studies on the effect of seizures on breathing. Bateman et al. demonstrated that pulse oximetry will show oxygen desaturations below $90 \%$ in $33.2 \%$ of all seizures, and such data was well demonstrated in several recent studies, pointing especially at GTCS that lead to a temporary decline in breathing efforts and reduced peripheral oxygenation [32-39]. Overall, postictal respiratory depression may be caused by multiple reasons not limited to anticonvulsive treatment [9]. Additionally, an inherent weakness to our study was that there was no specific timeframe in which oxygen levels were to be measured, rendering a more specific statement with regard to post-in-MDZ oxygenation difficult. Data may also have been altered due to inadequate positioning of the pulse oximeter or displacement during ictal movement due to body position changes [40, 41]. Overall, we did not observe a need for assisted breathing in any patient.

Other than oxygenation, the most common adverse event patients encountered was nasal irritation. This is caused by a need for the midazolam formulation to be acidic in order to be water soluble [42], but may also be independent of the medication given that it may stem from the application of larger volumes of liquids into the nasal cavity [43]. It could thus be observed in most patients but many may be oblivious to it because of the reduced vigilance during and after a seizure [33]. Its occurrence may be lessened by the addition of lidocaine to the solution as suggested by Humphries 
et al. [6], although this approach requires further investigation. Recently, a ready-made formulation of in-MDZ was approved by the United States Food and Drug Administration (FDA) (Nayzilam ${ }^{\circledR}$; UCB, Brussels, Belgium) to treat acute repetitive seizures [44]. Nayzilam offers $5 \mathrm{mg}$ of midazolam per puff. The new formulation solved the problem of the low $\mathrm{pH}$ value by use of other solvents, resulting in a $\mathrm{pH}$ range between 5.0 and 9.0, and therefore the side effect of nasal irritation should not occur. Furthermore, use of buccal midazolam can avoid this problem of nasal irritation; however, buccal midazolam is only licensed to children and adolescents below the age of 18 years. Another alternative is the recently FDA-approved intranasal diazepam spray (Valtoco ${ }^{\circledR}$; Neurelis, Inc., San Diego, CA, USA) [45].

Due to its retrospective design, this study has inherent limitations, as we were not able to randomize or blind the administration of in-MDZ and we did not screen for all possible adverse effects. Although we protocolled in detail the delivery of in-MDZ and the administration of other ASDs, we did not systematically obtain serum levels. However, this is offset by the detailed video and EEG analysis. Furthermore, the study results are not generalizable to individuals with first seizure as the analyzed patients suffered from known epilepsy, an analysis for different etiologies was also not possible due to limited numbers.

In search of new delivery routes, Dhir et al. [46] suggested that intrapulmonal midazolam might be even more efficient as the lung is more vascularized than the nasal mucosa and the drug reaches the arterial blood system directly via this approach. Intrapulmonary delivery is currently under investigation in phase II trials [47]. It must be noted that anatomical differences in patients may render intrapulmonal drug delivery more difficult in children or geriatric patients [47], and seizure-related respiratory changes such as hypopnea, insufficient depth of breathing, or secretion may alter the rate of absorption [36]. To date, in-MDZ remains a preferable alternative, allowing for the easy administration of emergency treatment and protection against damaging subsequent seizures.

\section{Conclusion}

In-MDZ is a reliable and safe anticonvulsive agent in epilepsy patients that can lower the likelihood of seizure occurrence within the upcoming $24 \mathrm{~h}$ following its administration. We did not observe any serious TEAEs and there was no need for assisted breathing after treatment with in-MDZ. In-MDZ can be administered very quickly by trained staff within 1-2 min after seizure onset. Better formulation of in-MDZ will help to reduce irritation of the nasal mucosa and thus increase patient comfort and use of this emergency medication.
Acknowledgements We are grateful to all of our colleagues and the staff at the epilepsy centers in Frankfurt and Marburg for their assistance in conducting this study.

\section{Compliance with Ethical Standards}

Funding This study was supported by a LOEWE Grant from the State of Hessen for the "Center for Personalized Translational Epilepsy Research" (CePTER), Goethe-University Frankfurt, Frankfurt am Main, Germany. There is no industry funding to report. Open Access funding provided by Projekt DEAL.

Conflicts of interest AvB, SF, EH, and ÜB do not report any conflicts of interest. LK reports non-financial support from Eisai and UCB. SK reports honoraria for speaking engagements from Desitin and UCB as well as educational grants from AD Tech, Desitin Arzneimittel, Eisai, GW, Medtronic, Novartis, Siemens, and UCB. JPZ reports a speaker's honorarium from Eisai. PSR reports speaking honoraria from Eisai and honoraria from Austrian Institute of Technology (AIT). SSB reports personal fees from UCB Pharma, Eisai, Desitin Pharma, LivaNova, and Zogenix. FR reports personal fees from Eisai, grants and personal fees from UCB, grants and personal fees from Desitin Pharma, personal fees and other from Novartis, personal fees from Medtronic, personal fees from Cerbomed, personal fees from ViroPharma and Shire, grants from the European Union, and grants from the Deutsche Forschungsgemeinschaft. AS reports personal fees and grants from Arvelle Therapeutics, Desitin Arzneimittel, Eisai, GW Pharmaceuticals, LivaNova, Marinus Pharmaceuticals, Medtronic, Sage Therapeutics, UCB Pharma, and Zogenix.

Ethical approval The study was approved by the ethics committee of the Goethe-University Frankfurt in accordance with the ethical standards laid down in the 1964 Declaration of Helsinki and its later amendments.

Informed consent Informed consent was waived by the ethics committee of the Goethe-University Frankfurt due to the retrospective nature of this study.

Open Access This article is licensed under a Creative Commons Attribution-NonCommercial 4.0 International License, which permits any non-commercial use, sharing, adaptation, distribution and reproduction in any medium or format, as long as you give appropriate credit to the original author(s) and the source, provide a link to the Creative Commons licence, and indicate if changes were made. The images or other third party material in this article are included in the article's Creative Commons licence, unless indicated otherwise in a credit line to the material. If material is not included in the article's Creative Commons licence and your intended use is not permitted by statutory regulation or exceeds the permitted use, you will need to obtain permission directly from the copyright holder. To view a copy of this licence, visit http://creativecommons.org/licenses/by-nc/4.0/.

\section{References}

1. Physicians Emergency, Committee Policies. Clinical policies subcommittee. Clinical policy. Ann Emerg Med. 2004;43(2):278-90. https://doi.org/10.1016/j.annemergmed.2003.10.045.

2. Daniel H, Lowenstein M, Alldredge B. Status epilepticus. New Engl J Med. 1998;338(14):970-6. 
3. Poukas VS, Pollard JR, Anderson CT. Rescue therapies for seizures. Curr Neurol Neurosci Rep. 2011;11(4):418-22. https://doi. org/10.1007/s11910-011-0207-x.

4. Strzelczyk A, Ansorge S, Hapfelmeier J, Bonthapally V, Erder $\mathrm{MH}$, Rosenow F. Costs, length of stay, and mortality of superrefractory status epilepticus: A population-based study from Germany. Epilepsia. 2017;58:1533-41. https://doi.org/10.1111/ epi.13837.

5. Schubert-Bast S, Zöllner JP, Ansorge S, et al. Burden and epidemiology of status epilepticus in infants, children, and adolescents: A population-based study on German health insurance data. Epilepsia. 2019;60:911-20. https://doi.org/10.1111/epi.14729.

6. Humphries LK, Eiland LS. Treatment of acute seizures: is intranasal midazolam a viable option? J Pediatr Pharmacol Ther. 2013;18(2):79-87. https://doi.org/10.5863/1551-6776-18.2.79.

7. Elisabeth R, Tréluyer JM, Pons G. Pharmacokinetic optimisation of benzodiazepine therapy for acute seizures. Focus on delivery routes. Clin Pharmacokinet. 1999;36(6):409-24. https://doi. org/10.2165/00003088-199936060-00003.

8. Anderson GD, Saneto RP. Current oral and non-oral routes of antiepileptic drug delivery. Adv Drug Deliv Rev. 2012;64(10):911-8. https://doi.org/10.1016/j.addr.2012.01.017.

9. McIntyre J, Norris E, Appleton R, et al. Safety and efficacy of buccal midazolam versus rectal diazepam for emergency treatment of seizures in children: a randomised controlled trial. Lancet. 2005;366:205-10.

10. Galvin GM, Jelinek GA. Midazolam: an effective intravenous agent for seizure control. Arch Emerg Med. 1987;4(3):169-72. https://doi.org/10.1136/emj.4.3.169.

11. Kadel J, Bauer S, Hermsen AM, et al. Use of emergency medication in adult patients with epilepsy: a multicentre cohort study from Germany. CNS Drugs. 2018;32(8):771-81. https://doi. org/10.1007/s40263-018-0544-2.

12. Kapur J, Macdonald RL. Rapid seizure-induced reduction of benzodiazepine and $\mathrm{Zn}_{2}{ }^{+}$sensitivity of hippocampal dentate granule cell GABAA receptors. J Neurosci. 1997;17(19):7532-7540. http://www.ncbi.nlm.nih.gov/pubmed/9295398\%0Ahttp://www. pubmedcentral.nih.gov/articlerender.fcgi?artid=PMC2892718.

13. Scott RC, Besag FMC, Boyd SG, Berry D, Neville BGR. Buccal absorption of midazolam: pharmacokinetics and EEG pharmacodynamics. Epilepsia. 1998;39(3):290-4.

14. Bhattacharyya M, Kalra V, Gulati S. Intranasal midazolam vs rectal diazepam in acute childhood seizures. Pediatr Neurol. 2006;34(5):355-9. https://doi.org/10.1016/j.pediatrneu rol.2005.09.006

15. Thakker A, Shanbag P. A randomized controlled trial of intranasal-midazolam versus intravenous-diazepam for acute childhood seizures. J Neurol. 2013;260(2):470-4. https://doi.org/10.1007/ s00415-012-6659-3.

16. Fişgin T, Gurer Y, Tezic T, et al. Effects of intranasal midazolam and rectal diazepam on acute convulsions in children: prospective randomized study. J Child Neurol. 2002;17(2):123-6. https://doi. org/10.1177/088307380201700206.

17. Kay L, Reif PS, Belke M, et al. Intranasal midazolam during presurgical epilepsy monitoring is well tolerated, delays seizure recurrence, and protects from generalized tonic-clonic seizures. Epilepsia. 2015;56(9):1408-14. https://doi.org/10.1111/epi.13088

18. Holsti M, Sill BL, Firth SD, Filloux FM, Joyce SM, Furnival RA. Prehospital intranasal midazolam for the treatment of pediatric seizures. Pediatr Emerg Care. 2007;23(3):148-53. https://doi. org/10.1097/PEC.0b013e3180328c92.

19. Kay L, Merkel N, Von Blomberg A, et al. Intranasal midazolam as first-line in-hospital treatment for status epilepticus: a pharmacoEEG cohort study. Ann Clin Transl Neurol. 2019;6:2413-25. https ://doi.org/10.1002/acn3.50932.
20. Holsti M, Dudley N, Schunk J, et al. Intranasal midazolam vs rectal diazepam for the home treatment of acute seizures in pediatric patients with epilepsy. Arch Pediatr Adolesc Med. 2010;164(8):747-53. https://doi.org/10.1001/archpediat rics.2010.130.

21. McMullan J, Sasson C, Pancioli A, Silbergleit R. Midazolam versus Diazepam for the treatment of status Epilepticus in children and young adults: a meta-analysis. Acad Emerg Med. 2010;17(6):575-82. https://doi.org/10.111 1/j.1553-2712.2010.00751.x.

22. Harbord MG, Kyrkou NE, Kay D, Coulthard KP. Use of intranasal midazolam to treat acute seizures in paediatric community settings. J Paediatr Child Health. 2004;40(9-10):556-8.

23. Mula M. The safety and tolerability of intranasal midazolam in epilepsy. Expert Rev Neurother. 2014;14(7):735-40.

24. Lahat $\mathrm{E}$, et al. Comparison of intranasal midazolam with intravenous diazepam for treating febrile seizures in children: prospective randomised study. BMJ. 2000;321(7253):83-6. https://doi. org/10.1136/bmj.321.7253.83.

25. Klem GH, Lüders HO, Jasper HH, Elger C. The ten-twenty electrode system of the International Federation. Electroencephalogr Clin Neurophysiol. 1999;10(2):371-5. https://doi. org/10.1016/0013-4694(58)90053-1.

26. Fisher RS, Cross JH, French JA, et al. Operational classification of seizure types by the International League Against Epilepsy: position paper of the ILAE Commission for Classification and Terminology. Z Epileptol. 2018;31(4):272-81. https://doi.org/10.1007/ s10309-018-0216-8.

27. von Elm E, Altman DG, Egger M, Pocock SJ, Gøtzsche PC, Vandenbroucke JP. The strengthening the reporting of observational studies in epidemiology (STROBE) statement: guidelines for reporting observational studies. PLoS Medicine. 2007;4:e296. https://doi.org/10.1371/journal.pmed.0040296.

28. Scheffer E, Berkovic S, Capovilla G, et al. Classificazione delle epilessie della International League Against Epilepsy: position paper della Commissione ILAE per la Classificazione e la Terminologia. Epilepsia. 2017;58(4):512-21. https://doi.org/10.1111/ epi.13709.

29. Strzelczyk A, Adjei P, Scott CA, et al. Postictal increase in T-wave alternans after generalized tonic-clonic seizures. Epilepsia. 2011;52:2112-7. https://doi.org/10.1111/j.1528-1167.2011.03266 .x.

30. Bancke LL, Dworak HA, Rodvold KA, Halvorsen MB, Gidal BE. Pharmacokinetics, pharmacodynamics, and safety of USL261, a midazolam formulation optimized for intranasal delivery, in a randomized study with healthy volunteers. Epilepsia. 2015;56(11):1723-31. https://doi.org/10.1111/epi.13131.

31. Knoester PD, Jonker DM, Van Der Hoeven RTM, et al. Pharmacokinetics and pharmacodynamics of midazolam administered as a concentrated intranasal spray. A study in healthy volunteers. Br J Clin Pharmacol. 2002;53(5):501-7. https://doi.org/10.104 6/j.1365-2125.2002.01588.x.

32. Kwan P, Arzimanoglou A, Berg AT, et al. Definition of drug resistant epilepsy: consensus proposal by the ad hoc Task Force of the ILAE Commission on Therapeutic Strategies. Epilepsia. 2010;51(6):1069-77. https://doi.org/10.111 1/j.1528-1167.2009.02397.x.

33. De Haan G, Van Der Geest P, Doelman G, Bertram E, Edelbroek P. A comparison of midazolam nasal spray and diazepam rectal solution for the residential treatment of seizure exacerbations. Epilepsia. 2010;51(3):478-82. https://doi.org/10.111 1/j.1528-1167.2009.02333.x.

34. Detyniecki K, Van Ess PJ, Sequeira DJ, Wheless JW, Meng TC, Pullman WE. Safety and efficacy of midazolam nasal spray in the outpatient treatment of patients with seizure clusters-a 
randomized, double-blind, placebo-controlled trial. Epilepsia. 2019;60:1797-808. https://doi.org/10.1111/epi.15159.

35. Gonzalez Castro LN, Mehta JH, Brayanov JB, Mullen GJ. Quantification of respiratory depression during pre-operative administration of midazolam using a non-invasive respiratory volume monitor. PLoS One. 2017;12(2):1-11. https://doi.org/10.1371/ journal.pone. 0172750 .

36. Devinsky O. Effects of seizures on autonomic and cardiovascular function. Epilepsy Curr. 2004;4(2):43-6.

37. Vilella L, Lacuey N, Hampson JP, et al. Incidence, recurrence, and risk factors for peri-ictal central apnea and sudden unexpected death in epilepsy. Front Neurol. 2019;10:1-13. https:// doi.org/10.3389/fneur.2019.00166.

38. Lacuey N, Zonjy B, Hampson JP, et al. The incidence and significance of periictal apnea in epileptic seizures. Epilepsia. 2018;59(3):573-82. https://doi.org/10.1111/epi.14006.

39. Bateman LM, Li CS, Seyal M. Ictal hypoxemia in localizationrelated epilepsy: analysis of incidence, severity and risk factors. Brain. 2008;131(12):3239-45. https://doi.org/10.1093/brain/ awn277.

40. Chan ED, Chan MM, Chan MM. Pulse oximetry: understanding its basic principles facilitates appreciation of its limitations. Respir Med. 2013;107(6):789-99. https://doi.org/10.1016/j. rmed.2013.02.004.

41. Mahr K, Bergmann MP, Kay L, et al. Prone, lateral, or supine positioning at seizure onset determines the postictal body position:
A multicenter video-EEG monitoring cohort study. Seizure. 2020;76:173-8. https://doi.org/10.1016/j.seizure.2020.02.008.

42. Reves J, Fragen R, Vinik H, Greenblatt D. Midazolam: pharmacology and uses. Anesthesiology. 1985;62(3):310-24.

43. Bailey AM, Baum RA, Horn K, et al. Review of intranasally administered medications for use in the emergency department. J Emerg Med. 2017;53(1):38-48. https://doi.org/10.1016/j.jemer med.2017.01.020.

44. U.S. Food and Drug Administration. NAYZILAM ${ }^{\circledR}$ (midazolam) nasal spray CIV US Prescribing Information. 2019:1-23. https:// www.accessdata.fda.gov/drugsatfda_docs/label/2019/211321s000 lbl.pdf.

45. U.S. Food and Drug Administration.VALTOCO $®$ (diazepam nasal spray), CIV US Precribing Information. 2020;1-28. https://www. accessdata.fda.gov/drugsatfda_docs/label/2020/211635s000lbl. pdf.

46. Dhir A, Zolkowska D, Rogawski MA. Seizure protection by intrapulmonary delivery of midazolam in mice. Neuropharmacology. 2013;73:425-31. https://doi.org/10.1016/j.neuropharm .2013.06.002.

47. Maglalang PD, Rautiola D, Siegel RA, et al. Rescue therapies for seizure emergencies: new modes of administration. Epilepsia. 2018;59:207-15. https://doi.org/10.1111/epi.14479.

\section{Affiliations}

\section{Anemone von Blomberg ${ }^{1,2} \cdot$ Lara Kay $^{1,2} \cdot$ Susanne Knake ${ }^{2,3} \cdot$ Sven Fuest $^{3} \cdot$ Johann Philipp Zöllner $^{1,2}$. Philipp S. Reif ${ }^{1,2}$. Eva Herrmann ${ }^{4}$ Ümniye Balaban ${ }^{4}$. Susanne Schubert-Bast ${ }^{1,2,5} \cdot$ Felix Rosenow $^{1,2}$. Adam Strzelczyk ${ }^{1,2,3}$}

1 Epilepsy Center Frankfurt Rhine-Main, Center of Neurology and Neurosurgery, Goethe-University Frankfurt, University Hospital Frankfurt, Schleusenweg 2-16, Haus 95, 60528 Frankfurt am Main, Germany

2 LOEWE Center for Personalized Translational Epilepsy Research (CePTER), Goethe-University Frankfurt, Frankfurt am Main, Germany
3 Epilepsy Center Hessen and Department of Neurology, Philipps-University Marburg, Marburg (Lahn), Germany

4 Institute for Biostatistics and Mathematical Modeling, Goethe-University Frankfurt, Frankfurt am Main, Germany

5 Department of Neuropediatrics, Goethe-University Frankfurt, Frankfurt am Main, Germany 